\title{
Phialophora verrucosa
}

National Cancer Institute

\section{Source}

National Cancer Institute. Phialophora verrucosa. NCI Thesaurus. Code C127739.

A species of dematiaceous fungi in the phylum Ascomycota that produces conidia from phialides with conspicuous darkened collarettes. This species is a causative agent of chromoblastomycosis. 